\title{
MEDICATION USE, SUBSTANCE USE, AND PSYCHOLOGICAL CONDITIONS OF FEMALE INMATES IN CANADIAN FEDERAL PRISONS $\left({ }^{1}\right)$
}

\author{
Chantal Plourde $\left({ }^{2}\right)$, Natasha Dufour $\left({ }^{3}\right)$, \\ Serge Brochu $\left({ }^{4}\right)$, AnNie Gendron $\left({ }^{5}\right)$
}

\section{Note}

The opinions and conclusions presented here do not necessarily reflect those of the Correctional Service of Canada.

\section{ACKNOWLEDGEMENTS}

We wish to thank the Fonds de recherche du Québec sur la société et la culture (FRQSC) and the Université du Québec à Trois-Rivières for their financial contributions to this research project.

${ }^{1}$ Correspondence concerning this article should be addressed to : Chantal Plourde, 3351 boulevard des Forges (1014a, M-S), P.O. Box 500 Trois-Rivières, Québec, Canada G9A 5H7, Telephone: 819-376-5011 ext. 4059 - Fax: 819-376-5210 - E-mail: chantal. plourde@uqtr.ca

${ }^{2} \mathrm{Ph} . \mathrm{D}$., Criminology, Researcher at the Group for Research and Intervention on Psychoactive Substances of Quebec (RISQ), the International Center for Comparative Criminology (CICC)-UQTR and the Centre Dollard-Cormier - University Institute on Addictions - Professor, Department of Psycho-education, University of Quebec at TroisRivières.

${ }^{3}$ M.D. FRCPC, Psychiatrist, Consultation-Liaison Services, University of Montreal Medical Center (CHUM).

${ }^{4} \mathrm{Ph} . \mathrm{D}$., Criminology, Researcher at the Group for Research and Intervention on Psychoactive Substances of Quebec (RISQ), the International Center for Comparative Criminology (CICC) and the Centre Dollard-Cormier - University Institute on Addictions Assistant Dean, Human Resources and Management, Faculty of Arts and Sciences - Professor, School of Criminology, University of Montreal.

5 Ph.D, Psychology, Researcher at Research and Strategic Development Center, École Nationale de Police du Québec. 


\section{Introduction}

The status of the physical and mental health of incarcerated women is highly concerning (Gunter, Philibert \& Hollenbeck, 2009; Robert, Frigon $\&$ Belzile, 2007). A recent American study reports that a higher proportion of incarcerated women, compared to incarcerated men, have physical health conditions $(56.8 \%$ vs. $40 \%$; cancer, hypertension, diabetes, arthritis, asthma, hepatitis, and cirrhosis) and mental health conditions (43.6\% vs. $21.6 \%$; depression, bipolar disorder, psychosis, posttraumatic stress, anxiety, and personality disorders) (Binswanger et al., 2010). In Canadian federal detention facilities, it is estimated that one in five women has a serious mental health disorder at the time of incarceration, representing an increase of over $61 \%$ in the last ten years (Folsom, 2010). Alcohol and drug abuse are also very common. Compared with incarcerated men, a higher percentage of incarcerated women $(59.3 \%$ vs. $52.7 \%)$ report problems with illicit substance use in the year preceding their incarceration, and they are also more likely to have used injectable drugs in their lives $(24.2 \%$ vs. $17.1 \%)$ (Binswanger et al., 2010). However, a higher percentage of incarcerated men than women $(47.9 \%$ vs. $36.9 \%)$ report problems with alcohol use prior to incarceration (Binswanger et al., 2010).

Additionally, the coexistence of multiple disorders is common in prison populations (Butler, Kariminia, Levy \& Murphy, 2004; Maruschak, 2006). For example, dependence on psychoactive substances (PAS) is highly associated with the presence of mental health disorders (Benswanger et al., 2010; Faust \& Magaletta, 2010; James \& Glaze, 2006; Karberg \& James, 2005; Taxman, Cropsey, Melnick \& Perdoni, 2008; Zlotnick et al., 2008). It is estimated that $80 \%$ of addicted female inmates have a serious addiction, and there is a concomitant diagnosis of psychiatric disorders in $70 \%$ of these cases (McDonagh, Noël \& Wichmann, 2002). It has also been reported that women who had a PAS use problem prior to incarceration were more likely to require psychiatric services during their imprisonment (Faust \& Magaletta, 2010).

Given the magnitude of health problems in the prison population, it is not surprising to find elevated rates of medication use within prisons. A study conducted by the Correctional Service of Canada on a randomly chosen day in 2001 indicated that $87 \%$ of female inmates had medical prescriptions (versus $45 \%$ of all female Canadians). The average number of prescriptions, including all medications, was 4.4 per inmate, with a 
median of 3 (Langner, Barton, McDonagh, Noël \&Bouchard, 2002). The most common prescriptions were for psychotropic and non-steroidal antiinflammatory medications, followed by peptic ulcer medication, antiasthmatic drugs, allergy medications, anti-anemia medications, contraceptives, narcotics, hormone replacement therapy, muscle relaxants, and migraine medication. When prescriptions for medications that could have been purchased over-the-counter (OTC) were excluded, $80 \%$ of the inmates were taking at least one medication that required a prescription (Langner et al., 2002). The authors have indicated, however, that this elevated number of medications may be explained by the status of some prescriptions placed in the files of these women under "as-needed" medications that may not be administered. As observed by Langner and collaborators (2002), considering the difficulties in obtaining access to prescription medications in prison (due in large part to the limited number of psychiatrists employed in penitentiaries), it is useful to create a form of preventive prescription that would allow prisoners access to medication as needed. Although also observed in the general population, this practice is likely more common in prisons.

Existing literature suggest that the level of substance use and prevalence of psychological disorders among female offenders is of great interest and little information is known about the phenomena of medication use within the prison. To our knowledge, no study has explored the connection between substance use prior to incarceration and the use of illicit substances or medications within prisons by incarcerated women. Therefore, the current report attempts to do the following: 1) describe the rate of prescription medication use during incarceration; 2) explore the relationship between prior substance use and the use of illicit substances or psychotropic medications during incarceration; and 3) test the differences in the mean severity scores for mental health disorders in connection with the presence of psychoactive substance use problem prior to incarceration and the use of psychotropic medications during incarceration.

\section{Method}

The present data are the result of an exploratory study conducted in five main Canadian federal women's penitentiaries between 2004 and 2006. Participants were recruited on a voluntary basis and, therefore, represent a convenience sample (Babbie, 1990). The combined total population of these facilities was 377 detainees at the time of recruitment. 
After excluding women held in isolation, those with severe mental disorders, and those who were released daily for social reintegration, we solicited the participation of 338 detainees and had a response rate of $52.1 \%$ ( $\mathrm{n}=176$ women). Although this response rate appears somewhat low, it is fairly similar to that typically expected in a general adult population, in which a mean response rate of $65 \%$ is expected (Trudel \& Antonius, 1991). Necessary ethics-related approvals were obtained from the Correctional Service of Canada and from the ethics committee of the Université du Québec à Trois-Rivières.

In the setting of an individual interview and accompanied by an interviewer, the respondents were invited to complete a questionnaire. The questionnaire included questions on alcohol and illicit substance use and a psychological scale borrowed from validated instruments: Alcohol Dependence Scale (ADS: $\alpha=0.95$ ) (Skinner \& Horn, 1984); Mandatory Drug Testing in Prisons (MDT: $\alpha=0.90$ ) (Edgar \& O'Donnell, 1998); Integral psychological scale of the Addiction Severity Index (ASI: $\alpha=$ 0.72) (McLellan, Lubborsky \& O'Brien, 1980) Completion of the questionnaire required an average of 30 minutes. During the interview, the respondents were asked to provide authorization allowing us to access their medical drug file cards for the prior three months. Among the 176 respondents, 169 agreed. The following analyses were performed on these 169 participants.

These files outlined all of the medications that had been prescribed for the women for physical or psychological health conditions since their incarceration. The analysis was restricted, however, to the 30 days preceding our visit to obtain a time frame equivalent to the evaluation of mental health conditions. Given the previously described tendency toward preventive prescriptions in detention facilities (Langner et al., 2002), we reviewed clinic notes on the administration of these medications to determine the proportion of prescriptions that were not administered during the previous 30 days. We did not attempt to evaluate a deviation from prescribed dosage, but rather to determine which prescribed medications were not used at least once during the study period. The listed medications were classified into various categories based on the Compendium of Pharmaceuticals and Specialties (CPS) according to their main effect (Canadian Pharmaceutical Association, 2005). The study team (consisting of a psychiatrist, a pharmacist, a nurse and researchers) formed a consensus on the classification of certain medications that could have two effects. For example, Epival, and Tegretol were classified as psycho- 
tropic, because prescribing physicians frequently use them for this purpose, whereas Gravol was classified as an antihistamine, although it can also have a sedative effect. Medications were then classified using the classification proposed by Langner et al (2002) to allow comparison of their results with a similar population.

The descriptive comparative analyses that follow were performed with a cutoff value of ş 1.96. As such, a $p$ value that was Ş 0.05 indicated a significant difference between the groups. When performing correlations, the Yule's Q coefficient (Siegel, 1988) was used to evaluate the strength of the significant relationships. Bonferroni's correction was also applied to tests of differences in means ( $t$ test). The threshold for acceptable significance to reject the null hypothesis was, therefore, $\mathrm{p}<0.025$.

\section{Results}

The average age of women in the subpopulation $(n=169)$ was 35.4 years $(s . d .=0.8)$ and followed a normal distribution according to the criteria of Curran, West \& Finch (1996). The women were mainly Caucasian $(63.3 \%)$, nearly a quarter identified as aboriginal $(22.5 \%)$, and $14.2 \%$ were of diverse ethnicity. More than half of the women were single $(54.4 \%), 17.2 \%$ were divorced or separated, $23.1 \%$ were married or in a relationship, and $5.3 \%$ were widowed. The sociodemographic status of the women in the study was comparable to that of the general Canadian female prison population (Mahony, 2011). Table 1 shows the participants' criminal characteristics. The duration of sentences represents the total time of incarceration without including the possibility of parole. Life sentences were estimated to represent 300 months (i.e., 25 years) of imprisonment.

\section{Medication use}

A review of the participants' medical drug file cards revealed that $90.1 \%$ of the women participants had at least one medication prescription. Among all the files, 300 different medications were listed, including those that would be available OTC outside of prison (e.g., antihistamines, ibuprofen, etc.) but required a prescription during incarceration. The average number of prescribed medications per file was 7.97 (median $=7$, range: 1 to 25$)$. The most frequently prescribed medications were intended to treat general physical health problems (e.g., endocrine 
Table 1

Respondents' Legal Characteristics

\begin{tabular}{|c|c|c|c|}
\hline & \multicolumn{2}{|c|}{ Women inmates $(n=169)$} \\
\hline & & Median & Range \\
\hline \multicolumn{2}{|c|}{ Sentence length (months) } & 41 & {$[12-300]$} \\
\hline \multicolumn{2}{|c|}{ (life sentences excluded) } & (36) & {$[12-255]$} \\
\hline \multicolumn{2}{|c|}{ Number of months since admission } & 7 & {$[1-294]$} \\
\hline \multicolumn{2}{|c|}{ Number of stays in federal detention } & 1 & {$[1-4]$} \\
\hline \multirow[t]{4}{*}{ Main crime } & Crime against persons & \multicolumn{2}{|c|}{$58.6 \%$} \\
\hline & Property crime & \multicolumn{2}{|c|}{$22.5 \%$} \\
\hline & Narcotics & \multicolumn{2}{|c|}{$16.0 \%$} \\
\hline & Other & \multicolumn{2}{|c|}{$3.0 \%$} \\
\hline
\end{tabular}

\section{Table 2}

Number of women with at least one prescription for a given category

\begin{tabular}{lcc}
\hline Category & $\mathrm{n}$ & $\%$ \\
\hline Medication for general physical health & 109 & 70.8 \\
\hline Psychotropic & 96 & 62.3 \\
\hline NSAIDs (non-steroidal anti-inflammatory drugs) & 87 & 56.5 \\
\hline Corticosteroids & 66 & 42.9 \\
\hline Anthibiotics & 58 & 37.7 \\
\hline Bronchodilators & 49 & 31.8 \\
\hline Analgesics & 44 & 28.6 \\
\hline Muscle relaxants & 33 & 21.4 \\
\hline Antihistamines & 34 & 22.1 \\
\hline Anti-migraine & 27 & 17.5 \\
\hline Narcotics & 22 & 14.3 \\
\hline Contraceptives & 21 & 13.6 \\
\hline Hormone replacement therapy & 21 & 13.6 \\
\hline Anti-smoking & 14 & 9.1 \\
\hline
\end{tabular}

\footnotetext{
* The present data were collected between 2004 and 2006, when the antismoking law was not in effect in prisons. Therefore, the data likely do not reflect the current situation.
} 
disorders and digestive disorders), followed by psychotropic and nonsteroidal antiinflammatory medications. More than half of the women with prescribed medications in their files had at least one prescription for the medications listed above, as shown in Table 2. Among those who had a prescription for psychotropic drugs in their files $(n=96)$, an average of two different psychotropics was listed (range: 1 to 6). In comparison, among those with a prescription for narcotics $(n=25)$, the average was only one (range: 1 to 4 ).

Table 3 shows that a large proportion of the prescriptions were administered to the inmates by the medical staff. Contrary to the findings of Langner and collaborators (2002), the current data indicate that "preventative" prescriptions were not highly prevalent. It is interesting to note that in the case of narcotics, psychotropics, and muscle relaxants, between $87.7 \%$ and $100 \%$ of the prescriptions were administered to the detainees. The anti-migraine medications, corticosteroids, and bronchodilators were the least likely to be administered, which is consistent with their typical usage on an as-needed basis.

Table 3

Administration of medication to inmates within the last 30 days

\begin{tabular}{lc}
\hline Categories & $\begin{array}{c}\text { Administered } \\
(\%)\end{array}$ \\
\hline Anti-smoking & 100 \\
\hline Narcotics & 100 \\
\hline Muscle relaxants & 97.5 \\
\hline Hormone replacement therapy & 93.3 \\
\hline Psychotropics & 89.9 \\
\hline Analgesics & 87.7 \\
\hline Antihistamines & 85.7 \\
\hline NSAIDs (non-steroidal anti-inflammatory drugs) & 84.3 \\
\hline Anthibiotics & 83.7 \\
\hline Contraceptives & 81.8 \\
\hline General health & 81.1 \\
\hline Anti-migraine & 71.9 \\
\hline Corticosteroids & 61.2 \\
\hline Bronchodilators & 50.0
\end{tabular}




\section{Substance use before and during incarceration}

Among the 169 women interviewed, $70.3 \%$ reported that they had consumed alcohol during the three months prior to their incarceration, and $60 \%$ reported having consumed it regularly (at least once a week for at least one month) during their lifetime (average age when regular alcohol use began $=15.56$ years [sd.: 4.35]). Furthermore, $68.5 \%$ reported having used illicit substances in the three months prior to their current incarceration, and a large majority $(82.8 \%)$ reported having used illicit substances regularly during their lifetime (average age when regular illicit substance use began $=16.13$ years $[s d .: 6.16]$ ). More than two thirds of the participants $(66.9 \%)$ described their substance use within the three months prior to incarceration as problematic. Regarding high-risk behaviors linked to illicit drug use before and during incarceration, $47.9 \%$ of the women report having ever shared injection devices in their lifetime. While none of the women reported having shared injection devices since the beginning of their current incarceration, $10.3 \%$ stated that they had done so during a previous incarceration.

A few women (11.4\%) from the sample indicated that they had used substances (alcohol or illicit substances) illegally in prison in the three months prior to the study. A significant correlation was found between the presence of substance use problem prior to incarceration and the use of psychoactive substances in prison, with $94.1 \%$ of women who illicitly consumed in prison reporting substance use prior to incarceration $\left(X_{(n=167,1)}^{2}=6.27, p<0.012\right)$. The Yule's $Q$ coefficient was 0.8 , indicating a strong correlation.

Furthermore, the analysis shows an association between substance use problem prior to incarceration, as reported by the respondents, and having a prescription for psychotropics in the medical file during incarceration. A significantly larger proportion of participants $(73.4 \%)$ with a prescription for at least one psychotropic medication reported that they had a substance use problem prior to incarceration as compared with women with no prescription for psychotropics $(26.6 \%)\left(X^{2}(\mathrm{n}=167,1)=\right.$ 4.64, $p<0.031)$. The Yule's Q coefficient was 0.34 , indicating the moderate strength of this correlation. However, no correlation was found between having at least one prescription for a psychotropic medication and the consumption of illicit substances within the last three months in prison. 


\section{Psychological conditions}

The ASI "psychological condition" scale was integrated into the questionnaire to collect data on the inmates' psychological health. The median score obtained, based on the past 30 days, was 0.14 , which reveals a rather low level of psychological problems. However, the range of results on this scale $(\min =0 ; \max =0.82)$ shows large variability among the participants. Table 4 displays the percentage of participants who reported having had a particular psychological problem during their lifetime and for the 30 days prior to the study. Anxiety disorders, cognitive disorders, and depression were the most prevalent problems during the previous 30 days. The results obtained regarding the lifetime prevalence of the disorders demonstrated a marked presence of psychological problems among these women.

Table 4

Psychological Scale of the Addiction Severity Index

\begin{tabular}{lcc}
\hline Scale & $\begin{array}{c}\text { Past 30 days } \\
(\%)\end{array}$ & $\begin{array}{c}\text { Lifetime } \\
(\%)\end{array}$ \\
\hline Anxiety or severe tension & 36.7 & 63.7 \\
\hline $\begin{array}{l}\text { Concentration, memorization and/or compre- } \\
\text { hension disorder }\end{array}$ & 33.9 & 53.0 \\
\hline Severe depression & 21.9 & 62.7 \\
\hline Violent behavior & 11.2 & 53.8 \\
\hline Suicidal thoughts & 5.3 & 53.3 \\
\hline Self-mutilation & 2.4 & 36.1 \\
\hline Hallucinations & 1.2 & 16.6 \\
\hline Suicide attempts & 0.6 & 51.5 \\
\hline
\end{tabular}

The clinical score obtained on this scale was linked to the use of psychotropic medications during incarceration. A significant difference in the ASI score (psychological) was found between the participants with at least one prescription for a psychotropic in their file $(0.27)$ and those with no prescriptions for these medications $(0.11)(t=5.38, d l=167$, $p$ S 0.001$)$. The scores for the first group indicate more psychological problems, which is consistent with the use of such medication. In addi- 
tion, the ASI score of women reporting substance use problem before incarceration $(0.24)$ was more severe than that of women $(0.13)$ without substance use problem $(t=3.30, d l=167, p$ Ş 0.001).

\section{Discussion}

Regarding the first objective of this study, we found that $90.1 \%$ of the women in the sample had prescriptions for medication and that $90.3 \%$ of these women had been prescribed more than one medication. This was not surprising because female inmates are more likely to be physically and psychologically ill than women in the community (Binswanger et al., 2010; Robert et al., 2007). It appears that medication compliance was widespread, especially in the case of narcotics, psychotropics, and muscle relaxants. The current results differ from the findings of Langner and collaborators. (2002) concerning preventive prescriptions; the present results show that the majority of the medications prescribed were administered to the inmates by the medical staff.

Further, regarding the second objective, it appears that preincarceration substance use problem was associated with the prescription of psychotropic medication in prison and illicit alcohol or drug use within prison. We did not find relation between having at least one prescription for a psychotropic medication and the consumption of illicit substances in prison. Our previous work has shown that a homeostatic effect can develop in relation to the availability and use of illegal and prescription drugs. Specifically, when it is easy to obtain drugs illegally in prison, inmates are less likely to report taking prescription medication (Plourde $\&$ Brochu, 2002). The reverse is also true. Given that only $11.4 \%$ of the women in the present study reported taking PAS illegally while incarcerated along with the high compliance rate shown for medical prescriptions, our analyses seem to point in this direction.

The results regarding the third study objective found that the presence of substance use problem prior to incarceration was linked to a higher severity of psychological disorders and higher use of psychotropic medications during incarceration. However, it is not possible here to clarify the developmental sequence of these disorders, although they are interrelated. The incarcerated women in this study reported relatively elevated levels of psychological problems, although it was a smaller percentage than that reported by Butler and collaborators (2006). It is difficult to compare these studies, however, due to conceptual differences in the 
functional definitions of these psychological problems (Pélissolo, 2009). Caution is advisable prior to concluding that the current participants had a lower incidence of psychological problems, especially given that the lifetime prevalence was distinctly higher. While we would argue that in general the prison environment may not be supportive for women with mental health problems, is it possible that the low rates of suicidal ideation during incarceration among participants, for example, are linked to the structure of life in prison, which may provide some support for women suffering from severe personality disorders. Do the way female inmates are treated and the psychological support they receive play a role in explaining this gap? Is it possible that, since they have been incarcerated for close to two years on average, active crises in their lives are less frequent and the situation is relatively stabilized for the moment. Even if this was the case, it is important to remember that difficulties that have been muted in prison may well emerge with the approach of release. The challenge is even greater for women who have a long prison term prior to release (Schantz \& Frigon, 2009).

Although solely derived from Canadian data from a study performed on a small number of incarcerated women, this study represents a first step toward the comprehension of a phenomenon that affects a particularly vulnerable population. To conclude, we think that effective services to this clientele should include an indepth evaluation to then develop a personalised treatment plan specific to the individual's psychoactive substance use, personality traits, cooccurring problems or motivation level. Moreover, despite certain limitations, particularly those concerning the motivation of convicted individuals and the difficulty of establishing a therapeutic alliance (Plourde, Brunelle \& Ledoux, 2010; Brochu \& Plourde, 2012), it seems to us that the judicial process represents an opportunity to reach a large number of individuals with substance dependence. The current results support the relevance of integrating treatment services for substance addiction and mental health in incarcerated women, as their concomitance is high (Faust \& Magaletta, 2010; Taxman et al., 2008; Zlotnick et al., 2008). This is fundamental even if planning aftercare monitoring and setting up specific follow-ups for people with co-occurring problems are also major issues to consider in the judicial system.

Several methodological limitations should be taken into account when interpreting the results of this study. First, the questionnaire used to measure psychological disorders relies on self-reporting, which is quite 
different from a clinical evaluation to identify pathology. It would have been interesting to verify, through structured interviews, whether the women met the criteria for drug addiction or abuse and exhibited welldocumented personality disorders or other psychiatric problems. Furthermore, it would be interesting to know whether the narcotics were prescribed for pain, as an agonist treatment, or as a "substitution" for heroin or another opiate. A specific and detailed analysis of the psychotropic drugs prescribed for each inmate might have allowed us to learn more about the underlying psychopathologies. It is also important to highlight that the number of months since incarceration for some of these women was relatively high, which may have reduced their ability to provide exact information about their rate of PAS use in the three months prior to incarceration. Finally, the collection of inmates' health data could be biased by the level of social desirability or by the low level of trust in others. However, similar to other authors, we believe that results obtained from self-administered questionnaires are valid (Allnut et al. 2008; Darke, 1998).

\section{REFERENCES}

Allnutt, S., Wedgewood, L., Wilhelm, K., \& Butler, T. (2008). Temperament, substance use and psychopathology in a prisoner population: Implications for treatment. Australian and New Zealand Journal of Psychiatry, 42(11), 969-975.

Babbie, E. R. (1991). Survey Research Methods. Belmont, CA: Wadsworth.

Binswanger, I. A., Merrill, J. O., Krueger, P. M., White, M. C., Booth, R. E., \& Elmore, G. (2010). Gender differences in chronic medical, psychiatric, and substance-dependence disorders among jail inmates. American Journal of Public Health, 100(3), 476-482.

Brochu, S., \& Plourde, C. (2012). L'offre de services aux adultes toxicomanes sous le coup de mesures judiciaires : un jeu de murs et de ponts. In S. Brochu, M. Landry, \& C. Patenaude (eds). L'intégration des services en toxicomanie (pp. 107-125). Québec, Canada: Presses de l'Université Laval.

Butler, T., Andrews, G., Allnutt, S., Sakashita, C., Smith, N. E., \& Basson, J. (2006). Mental disorders in Australian prisoners: A comparison with community sample. Australian and New Zealand Journal of Psychiatry, 40, 272-276.

Butler, T., Kariminia, A., Levy, M., \& Murphy, M. (2004). The self-reported health status of prisoners in New South Wales. Australian and New Zealand Journal of Psychiatry, 28, 344-350.

Canadian Pharmaceutical Association. (2005). Compendium of pharmaceuticals and specialities. Toronto, Canada: Canadian Pharmaceutical Association. 
Curran, P. J., West, S. G., \& Finch, J. F. (1996). The robustness of test statistics to nonnormality and specification error in confirmatory factor analysis. Psychological Methods, 1(1), 16-29.

Darke, S. (1998). Self-reports among injecting drug users: A review. Drug Alcohol Depend, 51, 253-263.

Edgar, K., \& O'Donnell, I. (1998). Mandatory drug testing in prisons: The relationship between MDT and the level and nature of drug misuse. London, England: Home Office Research Study.

Faust, E., \& Magaletta, P. R. (2010). Factors predicting levels of female inmates' use of psychological services. Psychological Services, 7(1), 1-10.

Folsom, J. (2010). Services de santé du SCC : la psychologie en prison. Retrieved from http://www.csc-scc.gc.ca/text/hlth/pip-2010-fra.shtml

James, D. J., \& Glaze, L. E. (2006). Mental health problems of prison and jail inmates (Report NCJ 213600). Washington, DC: U.S. Department of Justice. Retrieved from http://bjs.ojp.usdoj.gov/content/pub/pdf/mhppji.pdf

Karberg, J., \& James, J. (2005). Substance dependance, abuse, and treatment of jail inmates (Report NCJ 209588). Washington, DC: US Department of Justice. Retrieved from http://bjs.ojp.usdoj.gov/content/pub/pdf/sdatji02.pdf

Gunter, T. D., Philibert, R., \& Hollenbeck, N. (2009). Medical and psychiatric problems among men and women in a community corrections residential setting. Behavioral Sciences and the Law, 27(5), 695-711.

Langner, N., Barton, J., McDonagh, D., Noël, C., \& Bouchard, F. (2002). Rates of prescribed medication use by women in prison. Forum on Corrections Research, 14(2), 10-14.

Mahony, H. T. (2011). Les femmes et le système de justice pénal (Report 89-503$\mathrm{X})$. Québec, Canada : Statistique Canada. Retrieved from http://www.statcan.gc.ca/pub/89-503-x/2010001/article/11416-fra.pdf

Maruschak, L. M. (2006). Medical problems of jail inmates (Report NCJ 210696). Washington, DC: US Department of Justice. Retrieved from http://bjs.ojp.usdoj.gov/content/pub/pdf/mpji.pdf

McDonagh, D., Noël, C., \& Wichmann, C. (2002). Mental health needs of women offenders: Needs analysis for the development of the intensive intervention strategy. Forum on Corrections Research, 14(2), 31-34.

McLellan, A. T., Lubborsky, L., \& O'Brien, C. P. (1998). Indice de gravité d'une toxicomanie (IGT) (J. Bergeron, M. Landry, S. Brochu, \& L. Guyon, Trans.). QC, Canada: Le RISQ.

Pélissolo, A. A. (2009). Les dépressions sévères: Quels concepts? Quels critères? L'Encéphale: Revue de psychiatrie clinique biologique et thérapeutique, 35(7), S243-S249.

Plourde, C., \& Brochu, S. (2002). Medicine and prison: Homeostasis of an environment. International Medical Journal, 9(3), 163-169.

Plourde, C., Brunelle, N., \& Ledoux, C. (2010). Drugs: Dealing with substance use problems among criminal offenders: Things to know. In M. HerzogEvans (ed). Transnational Criminology (Vol. 3, pp. 565-592). Nijmegen Wolf Legal Publishers. 
Robert, D., Frigon, S., \& Belzile, R. (2007). Women, the embodiment of health and carceral space. International Journal of Prisoner Health, 3(3), 176-188.

Schantz, L. R., \& Frigon, S. (2009). Aging, women and health: From the pains of imprisonment to the pain of reintegration. International Journal of Prisoner Health, 5(1), 3-15.

Siegel, S., \& Castellan, J. J. (1998). Nonparametric statistics for behavioral sciences $\left(2^{\text {nd }}\right.$ ed). New York, NY: McGraw Hill.

Skinner, H. A., \& Horn, J. L. (1984). Alcohol Dependence Scale (ADS) user's guide. Toronto, Canada: Addiction Research Foundation.

Taxman, F. S., Cropsey, K. L., Melnick, G., \& Perdoni, M. L. (2008). COD services in community correctional settings: An examination of organizational factors that affect service delivery. Behavioral Sciences and the Law, 26(1), 35-55.

Trudel, R., \& Antonius, R. (1991). Méthodes quantitatives appliquées aux sciences humaines. Montréal, Canada : Centre éducatif et culturel.

Zlotnick, C., Clarke, J. G., Friedmann, P., Roberts, M. B., Sacks, S., \& Melnick, G. (2008). Gender differences in comorbid disorders among offenders in prison substance abuse treatment. Behavioral Sciences and the Law, 26(4), 403-412.

\section{SUMMARY}

This study provides data on substance use patterns, including medications, among female inmates in Canadian federal prisons. The participants were interviewed regarding their substance use and their psychological condition before and during incarceration. Their medication cards were also analyzed. The results show that a large proportion $(66.9 \%)$ of these incarcerated women reported substance abuse prior to incarceration and exhibited psychological disorders. In prison, if the illicit substance use remained low, most subjects had prescriptions for more than one medication. Furthermore, women with psychotropic medication prescriptions in their file had, on average, prescriptions for two different psychotropic medications. Significant relationships were found between substance misuse before incarceration and illicit substance use or and psychotropic medication use during incarceration. These results support the need to develop integrated services for both addiction and mental health for female offenders during incarceration.

Key words: medication; substance use and abuse; women; prisons; mental health

\section{RÉSUMÉ}

Cette étude décrit les habitudes de consommation de substances psychoactives des détenues incarcérées dans les pénitenciers fédéraux canadiens. Les participantes ont été interrogées au sujet de leur utilisation de substances psychoactives et de leur état psychologique avant et pendant l'incarcération. Leur fiche de 
médicaments prescrits a également été analysée. Les résultats montrent qu'une grande proportion $(66,9 \%)$ de ces femmes incarcérées a rapporté des problèmes de dépendance ainsi que des troubles psychologiques avant leur incarcération. Durant leur période d'incarcération, bien que la consommation de substances illicites est demeurée relativement faible, un grand nombre de femmes recevait des médicaments psychoactifs prescrits par les services de santé de l'établissement. Celles qui bénéficiaient de prescriptions de médicaments psychotropes recevaient, en moyenne, deux psychotropes différents. Des relations significatives ont été trouvées entre l'abus de substances avant l'incarcération et l'utilisation de substances illicites et de médicaments psychotropes prescrits au cours de l'incarcération. Ces résultats confirment la nécessité de développer des services intégrés à la fois pour la toxicomanie et la santé mentale pour les délinquantes pendant leur incarcération.

\section{RESUMEN}

Este estudio describe los hábitos de consumo de sustancias psicoactivas por parte de internas en centros penitenciarios federales en Canadá. Se ha preguntado a las participantes sobre la utilización de las sustancias psicoactivas y su estado psicológico antes y durante el internamiento. Asimismo, se han analizado sus fichas de prescripción de medicamentos. Los resultados muestran que una gran parte de estas mujeres internas (un 66,9\%), han tenido problemas de dependencia así como trastornos psicológicos antes de su internamiento en el centro penitenciario. Durante su periodo de encarcelamiento, aunque el consumo de sustancias ilícitas se mantuvo relativamente bajo, un gran número de mujeres recibía medicamentos psicoactivos prescritos por los servicios de salud del establecimiento. Las que se beneficiaban de prescripciones de medicamentos psicotrópicos recibían, de media, dos psicotrópicos diferentes. Se han encontrado relaciones significativas entre el abuso de sustancias ilícitas y la prescripción de medicamentos psicotrópicos durante el internamiento. Estos resultados confirman la necesidad de desarrollar servicios integrados a la vez para la toxicomanía y para la salud mental destinados a las delincuentes durante su encarcelamiento. 